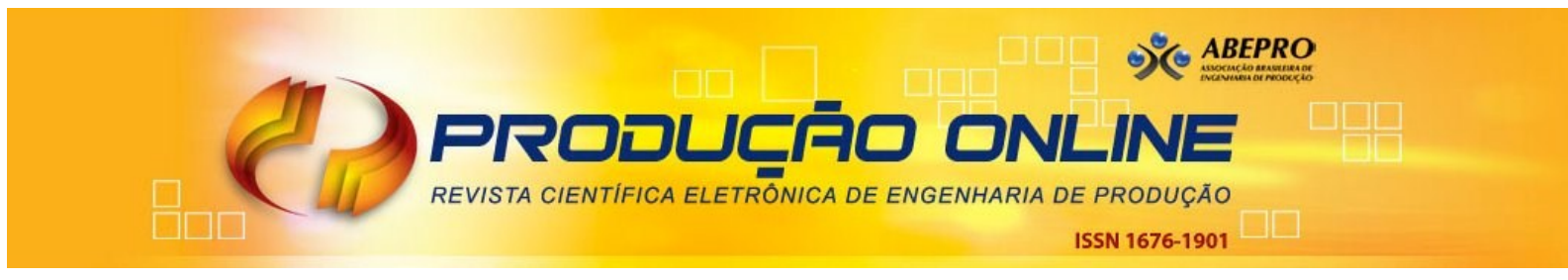

\title{
GUIA DE REFERÊNCIA PARA O DESENVOLVIMENTO DE PRODUTOS PARA PORTADORES DE DEFICIÊNCIA VISUAL
}

\section{GUIDELINE FOR THE DEVELOPMENT OF PRODUCTS FOR VISUALLY IMPAIRED}

\author{
Ana Carolina Richter do Nascimento* E-mail: anacarolinarichter@gmail.com \\ Carlos Cziulik*E-mail: cziulik@utfpr.edu.br \\ *Universidade Tecnológica Federal do Paraná (UTFPR), Curitiba, PR
}

\begin{abstract}
Resumo: A preocupação com os Portadores de Necessidades Especiais (PNEs) tem crescido nos últimos anos, no mundo e no Brasil. Mecanismos governamentais e legais buscam tratar formalmente o assunto. Os PNEs integram diferentes categorias, dentre as quais no Brasil os deficientes visuais representam 67,3\% (IBGE, 2002). Estes, por sua vez, precisam interagir com diferentes produtos, existindo iniciativas que contemplam estas demandas. Porém, existe grande carência de produtos industrializados para este grupo no Brasil (ITS, 2007), o que se percebe é a adaptação de produtos convencionais para demandas específicas do DV. As abordagens de desenvolvimento de produto, em sua maioria, não tratam de aspectos específicos quando o cliente usuário é um deficiente visual. Assim, o objetivo do presente artigo é apresentar o desenvolvimento e aplicação de um Guia de Referência para o desenvolvimento de produtos para portadores de deficiência visual. $\mathrm{O}$ modelo proposto é derivado de referenciais teóricos, análise de produtos e levantamento de campo, sendo estruturado em grupos de aplicação e desmembrados em subgrupos, direcionando o projetista à recomendação correta. A recomendação é descrita e exemplos de aplicação são disponibilizados. Uma aplicação descritiva caracteriza o funcionamento do guia proposto. Resultados preliminares de uma aplicação experimental indicam que o Guia de Referência aqui desenvolvido é: i. coerente para com os produtos já comercializados e recomendados para o deficiente visual; ii. aplicável para o público-alvo para o qual é destinado (projetistas com e sem experiência); iii. aplicável na fase de projeto que é direcionado (Projeto Conceitual); iv. instrumento para melhoria na qualidade das concepções de produto e para a diminuição do tempo despendido em um projeto.
\end{abstract}

Palavras-chave: Desenvolvimento de produto. Guia de Referência. Deficiente visual.

\begin{abstract}
The concern about the needs of disabled people has grown, worldwide and in Brazil. The government seeks to address this issue. Visually impaired people represent $48,1 \%$ of the disabled person group in Brazil. Brazilian products that are used by visually impaired people are not developed specifically for this group and this fact is a big gap. Predominantly, product development approaches do not study methodologies to design products for people that can not see. Therefore, the objective of this paper is the development and application of a guideline for the development of products for visually impaired people. The proposed model is the result of literature review and product analysis. The Guideline is structured in groups and subgroups, helping the designer to find the correct recommendation. Each recommendation has a description and example. An illustrative application shows how the guideline works. An experimental application illustrates that the proposed guideline is: i) consistent with the recommended products for the visually impaired people; ii) applicable for experienced and novice designers; iii) applicable for the "Conceptual Design" phase; iv) tool for improve the quality of product conception and for reducing the design lead time.
\end{abstract}

Keywords: Product Development. Guideline. Visually impaired people. 


\section{INTRODUÇÃO}

Estima-se que, no Brasil, existam 24,5 milhões de Portadores de Necessidades Especiais (PNEs) representando 14,5\% da população (IBGE, 2002). Considera-se como PNE, o indivíduo que possui algum tipo de deficiência, seja ela mental, auditiva, visual ou física.

Atualmente, são freqüentes os questionamentos sobre como esta parcela da população relaciona-se com a infraestrutura disponível e também, sobre como adaptar os produtos existentes ou projetar novos para este usuário específico.

Esta tendência à mudança de conceitos com relação à deficiência podem ser verificadas pela atual e constante aprovação de leis, criação de órgãos no governo e publicação de normas e especificações. Mundialmente, pode-se citar a Convenção sobre os Direitos das Pessoas com Deficiência adotada pela ONU em 2006 (FUNDAÇÃO DORINA NOWILL PARA CEGOS, 2011). Já, no Brasil, a Lei $n^{\circ}$ 7.853/89 e o Decreto $n^{\circ} 3.298 / 99$ regulamentam a acessibilidade a pessoas com qualquer tipo de deficiência (ibidem). Também, existe a Coordenadoria Nacional para a Integração da Pessoa Portadora de Deficiência (CORDE), o Decreto-Lei $n^{\circ}$ 5.296 também conhecido como Lei de Acessibilidade e a norma NBR 9050 (disponibilizada pela Associação Brasileira de Normas Técnicas) (ibidem).

A aplicação de normas e regulamentações com o objetivo de garantir o cotidiano normal dos PNEs assume um contexto mundial. Pode-se citar os Estados Unidos como exemplo. Constantemente a indústria americana desenvolve produtos que, desde sua concepção são direcionados às necessidades mais específicas dos portadores de necessidades especiais sendo que são produzidos industrialmente em larga escala o que resulta em um maior alcance comercial do produto.

Estabelecendo uma comparação, no Brasil a maioria dos produtos para os PNEs são versões adaptadas de produtos para usuários correntes ou produzidos artesanalmente por pequenos grupos locais. Assim, os produtos disponíveis no mercado brasileiro especialmente planejados para o PNE são importados. Segundo pesquisa realizada pelo ITS (2007) sabe-se que grande parte das pesquisas realizadas com relação a produtos e meios para os PNEs não alcançam a indústria e comercialização pois não atravessam o limiar acadêmico, existindo a urgente 
necessidade do incentivo a inovação, desenvolvimento e industrialização de pesquisas neste segmento.

Por sua vez, as abordagens de PDP (Processo de Desenvolvimento de Produto) não possuem, em sua maioria, mecanismos específicos para tratar aspectos relativos ao desenvolvimento de produtos para PNEs.

Dentre todos os PNEs, aqueles que merecem maior atenção quanto ao desenvolvimento de produtos específicos são os deficientes visuais (DVs) uma vez que, segundo a Organização Mundial da Saúde (OMS), é estimada a existência de 284 milhões de pessoas com deficiência visual no mundo das quais 39 milhões possuem cegueira total e 245 milhões possuem algum tipo de deficiência visual parcial (WORLD HEALTH ORGANIZATION, 2011).

No Brasil, segundo o Instituto Brasileiro de Geografia e Estatística é estimada a existência de 159 mil pessoas com cegueira total e 16,5 milhões com algum tipo de deficiência visual parcial (IBGE, 2002) o que significa que dentre o grupo de PNE brasileiros, mais da metade são deficientes visuais $(67,3 \%)$.

Conforme dados do ITS (2007), a maioria das pesquisas realizadas no Brasil em tecnologia para os PNEs é direcionada ao PNE com deficiência na função muscular, não correspondendo a realidade brasileira, uma vez que a maioria dos PNEs é representada pelo deficiente visual, estabelecendo uma grande lacuna.

Visando acompanhar e oferecer suporte a esta demanda, o objetivo deste artigo é apresentar a proposta, estrutura e composição de um Guia de Referência para o desenvolvimento de produtos para pessoas com deficiência visual.

Espera-se que com a finalização desta investigação possa-se assegurar: i. o incentivo ao desenvolvimento de produtos específicos para o DV. ii. o suporte ao projeto de produtos para o deficiente visual. Assim, por meio do desenvolvimento deste trabalho procura-se oferecer à indústria brasileira um mecanismo diferenciado para o desenvolvimento de novos produtos direcionados as necessidades específicas do DV, possibilitando a abertura de um novo segmento de mercado.

Este artigo está estruturado em cinco seções. Na seção 2 são examinados e comparados aspectos relevantes para o desenvolvimento do Guia proposto. O Guia de Referência desenvolvido é apresentado na seção 3. Como consequência do trabalho realizado, a seção 4 contém a descrição de uma aplicação descritiva e 
outra experimental, empregando o Guia de Referência. Por fim, na seção 5 são apresentadas as considerações finais.

Quanto à metodologia utilizada, o Guia de Referência foi desenvolvido seguindo sequência de atividades conforme Figura 1. Inicialmente, uma busca por referenciais teóricos foi realizada orientando-se por dois macro temas, o PDP (processo de desenvolvimento de produto) direcionado ao PNE e o DV (deficiente visual) como usuário. A partir disto, para o primeiro tema foram verificados sub temas como: i) etapas do PDP; ii) guias de referência; iii) desenho universal; iv) tecnologia assistiva. Para o segundo tema foram verificados: i) pesquisa e desenvolvimento da tecnologia voltada ao deficiente visual no Brasil; ii) produtos existentes para o deficiente visual no Brasil e nos EUA; iii) a interface entre o deficiente visual e produtos do dia a dia; iv) os sentidos restantes com os quais o deficiente visual relaciona-se com o mundo.

Figura 1 - Sequência de atividades para o desenvolvimento do Guia proposto O DEFICIENTE VISUAL COMO USUÁRIO

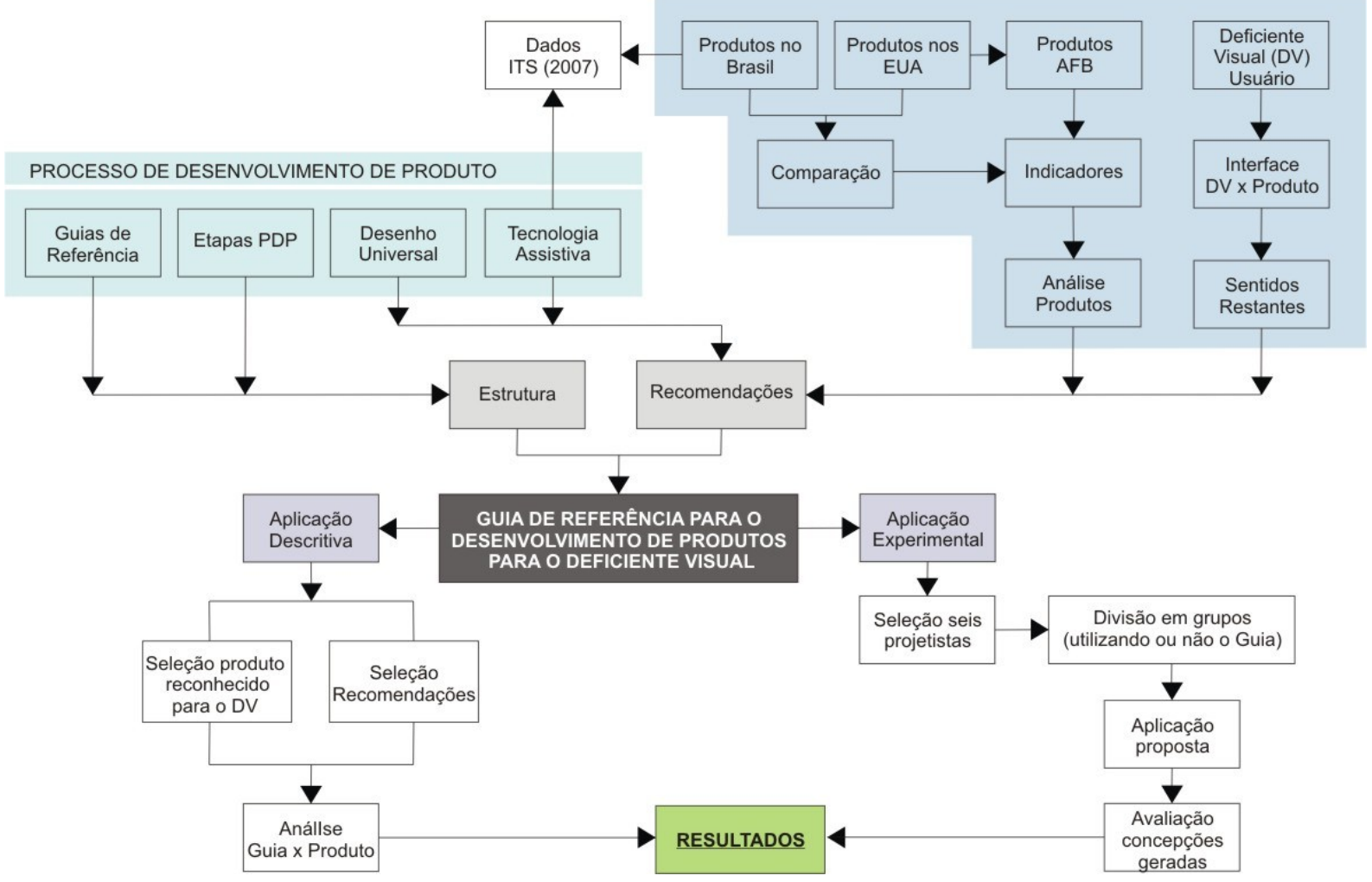

Uma vez os dados coletados, foi possível comparar os produtos existentes para o DV no Brasil e nos EUA. Finalizando esta comparação, pode-se constatar a 
atual defasagem do mercado brasileiro de produtos para o DV em relação ao americano. Posteriormente, um banco de dados americano disponibilizado pela American Foundation for the Blind $(A F B)$ ofereceu exemplos de produtos recomendados para $\circ$ DV. Assim, estes exemplos passaram por análise realizada por meio de um modelo proposto pelos autores que verifica o atendimento ou não a cinco termos (indicadores) que concatenam benefícios pretendidos pelo produto ao DV.

A elaboração do Guia foi iniciada a partir de sua estruturação, ou seja, a partir da organização e definição de como cada recomendação seria disponibilizada para leitura e análise. A estrutura baseou-se nos referenciais teóricos e nas necessidades particulares do Guia em questão, destinado a projetistas com variados níveis de experiência a ser aplicado na fase do Projeto Conceitual.

A atividade seguinte consiste na escrita de cada recomendação de projeto, com base na pesquisa realizada, referenciando boas características de produtos recomendados pela $A F B$ e princípios do Desenho Universal.

Por fim, após elaboração e organização o Guia de Referência desenvolvido pode ser submetido a duas aplicações, a primeira descritiva (com o objetivo de verificar seu funcionamento e compatibilidade com o mercado de produtos para o DV) e a segunda experimental (com objetivo de verificar sua aplicabilidade). Os resultados foram extraídos das duas aplicações e são apresentados na seção 4.3.

\section{O PROJETO DE PRODUTO DIRECIONADO A PORTADORES DE NECESSIDADES ESPECIAIS}

Para o desenvolvimento do Guia foi conduzida uma busca a referenciais teóricos que abordam temas distintos, como o PDP, sistema sensorial humano, entre outros, e que contribuem para que o objetivo do presente artigo seja atingido.

\subsection{Processo de Desenvolvimento de Produto}

Define-se como Processo de Desenvolvimento de Produto (PDP), o processo que abrange desde a afirmativa da necessidade de um determinado produto, sua concepção, viabilização e consequente lançamento no mercado. 
Torna-se fundamental verificar este tema uma vez que o objetivo do presente artigo é o desenvolvimento de um Guia de Referência para projeto, sendo este, uma ferramenta de grande utilidade se inserido em uma das etapas do PDP.

O PDP é foco de pesquisa de diversos autores como Rozenfeld et al. (2006), Pahl et al. (2005), Pugh (1991) e Baxter (2000), sendo o principal resultado de suas produções os chamados modelos de referência. Segundo Salgado et al. (2010) um modelo de referência é a união das melhores práticas relacionadas a um processo de desenvolvimento, sendo apresentada de forma objetiva e prática para qualquer participante ou usuário deste processo.

Normalmente o PDP é divido em macro fases e estas são subdivididas em fases e atividades. Para o presente artigo, o modelo de Rozenfeld et al. (2006) foi escolhido como base. Neste modelo, os autores propõem as macro fases: PréDesenvolvimento, Desenvolvimento e Pós-Desenvolvimento. Contidas nestas três macro fases estão as etapas: i. Planejamento de Projeto; ii. Projeto Informacional; iii. Projeto Conceitual; iv. Projeto Detalhado; v. Preparação para Produção; vi. Lançamento no Mercado.

Segundo Alvarenga (2006), a resposta da indústria é vagarosa em relação a adotar o PDP dedicado ao projeto inclusivo. Reforçando esta afirmativa, uma pesquisa realizada por Donga ${ }^{a}$ et al. (2003) relata que apesar da indústria aparentar certa identificação com os princípios do projeto inclusivo, ela considera impraticável adotar suas práticas. Este fato é justificado pelas seguintes barreiras: i. Falta de recursos financeiros; ii. Tempo de implementação; iii. O difícil acesso aos usuários; iv. A falta de projetistas qualificados e informados sobre o assunto.

$\mathrm{Na}$ obra de Alvarenga (2006) é proposto um modelo de PDP dedicado ao projeto inclusivo, no entanto, pode-se afirmar que para o desenvolvimento de produtos para DVs não há nos modelos de PDP tradicionais uma abordagem específica. Portanto, existe a oportunidade de estudo e desenvolvimento de novos recursos para este segmento específico de produto, de forma a alimentar um futuro modelo de PDP específico para o usuário DV. Existem vários recursos que podem ser empregados durante o PDP (e.g. Casa da Qualidade, Matriz Morfológica, entre outros). Dentre estes, um mecanismo interessante para a oportunidade verificada é o Guia de Referência uma vez que é utilizado para agregar mais qualidade a 
produtos concebidos e reduzir o tempo de projeto despendido (ver item 2.1.1), neutralizando assim, os pontos críticos apontados por Donga et al. (2003) e que dificultam a implantação do projeto inclusivo na indústria.

\subsubsection{Guias de Referência}

Segundo Cziulik; Princival (2008) um Guia de Referência tem como objetivo orientar, conduzir e direcionar ações em uma situação específica de projeto, proporcionando suporte ao projetista ou a equipe. Ainda, segundo estes autores, existem diversos momentos no PDP para se aplicar um Guia de Referência, sendo este mais frequentemente utilizado após a etapa de Projeto Conceitual gerando uma grande lacuna nesta fase, uma vez que sem o devido suporte, a etapa de Projeto Conceitual pode despender demasiadamente tanto recursos financeiros como de tempo caso um direcionamento assertivo não seja tomado.

Assim pode-se considerar como um Guia de Referência de projeto um conjunto de informações (de natureza diversificada) relevantes agrupadas de acordo com o contexto de aplicação. Os Guias de Referência clássicos no segmento de desenvolvimento de produto são:

a) O modelo proposto por Bralla (BRALLA, 1999) contém um grande número de guias de referência para cada tipo de processo de fabricação e material. Dentro de cada guia (em capítulos) existem recomendações de projeto que visam à economia e otimização na fase de manufatura. Ainda, Bralla disponibiliza exemplos da aplicação correta e incorreta de cada recomendação (Figura 2).

Figura 2 - Modelo de Bralla (exemplificação ilustrativa da recomendação)

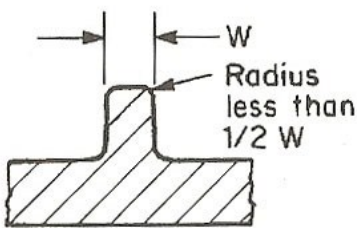

Not this

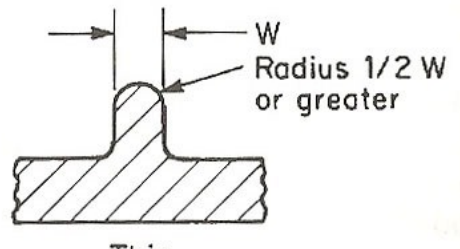

This

Fonte: Bralla (1999) 
b) O modelo proposto por Baxter (BAXTER, 2000) disponibiliza Guias de Referência na forma de recomendações teóricas, exemplificações da utilização de ferramentas (Figura 3) e estudos de caso realizados na indústria.

Figura 3 - Trecho de exemplo Análise FISP na obra de Bralla

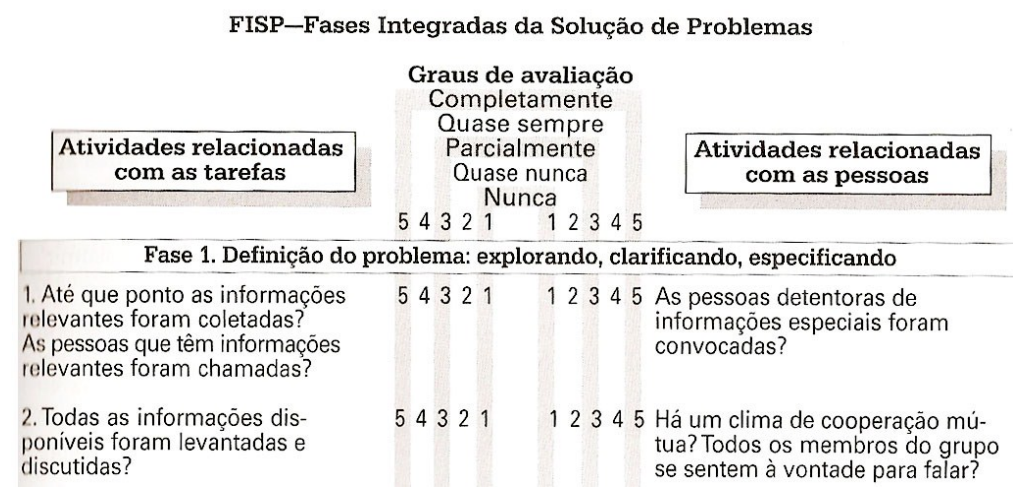

Fonte: Baxter (2000)

c) O modelo proposto por Pahl (PAHL et al., 2005) é dividido por contexto de aplicação, oferecendo pesquisa e compilação de dados. Pahl dispõe como Guia de Referência grande variedade de ferramentas e métodos juntamente a exemplos descritivos e ilustrativos (Figura 4) da aplicação de cada guia.

Figura 4 - Modelo para elaboração de lista de requisitos na obra de Pahl et al.

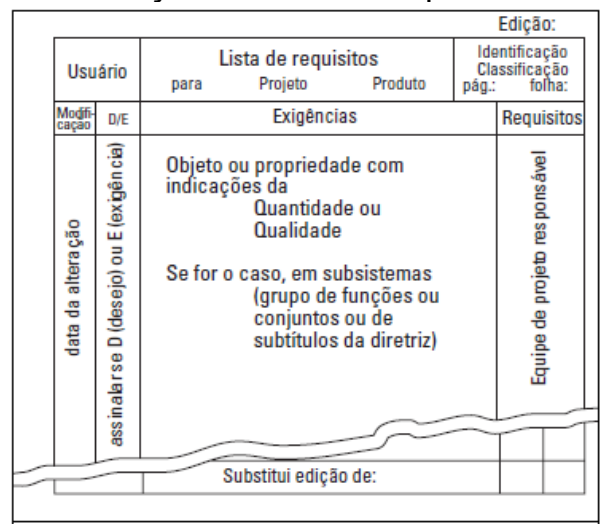

Fonte: Pahl et al. (2005)

d) O modelo proposto por Ashby (1992) para seleção de materiais propõe diagramas combinando variáveis, e.g.: resistência em função da 
densidade. Esta combinação resulta no diagrama o direcionamento ao material adequado em relação a combinação dos parâmetros desejados (CALLISTER, 2002).

e) Como exemplo do cotidiano da indústria, pode-se citar o modelo $A P Q P$ (Advance Product Quality Planning), sistema para o desenvolvimento de produtos estruturado em procedimentos e técnicas a serem realizados (FMEA de projeto e de processo, fluxograma de processo, teste de validação, entre outros) na forma de um check list, gerenciando a qualidade no desenvolvimento do produto (FORD, 2003).

\subsection{Projeto para portadores de necessidades especiais}

Conforme ressaltado na Seção 1, o interesse da sociedade e governo sobre as particularidades do cotidiano do PNE é algo recente no Brasil. Alguns conceitos mundialmente discutidos têm origem antiga e formalizam a necessidade de mudança no pensamento sobre a relação do indivíduo com os produtos e ambiente.

Uma das principais vertentes desta tendência é o Desenho Universal. Segundo Bernardi e Kowaltowski (2005), o Desenho Universal baseia-se em um conceito existente desde os anos 50, firmado na década de 80 por Ron Mace. Também chamado de Projeto Inclusivo, o Desenho Universal é o ato de projetar ambientes, produtos e comunicação de modo que estes tenham determinadas características que ofereçam condições de uso igualitário para todos. Baseia-se em sete princípios: i. uso equitativo; ii. flexibilidade de uso; iii. uso intuitivo; iv. informação perceptível; v. tolerância ao erro; vi. baixo esforço físico; vii. tamanho e espaço para acesso e uso.

Outra vertente relacionada a produtos, processos e outros meios projetados para o PNE é o conceito da Tecnologia Assistiva, a TA. Sendo um termo ainda novo, identifica-se como TA "[...] todo o arsenal de recursos e serviços que contribuem para proporcionar ou ampliar habilidades funcionais de pessoas com deficiência e conseqüentemente promover vida independente e inclusão" (BERSCH, 2008, pg 2). 
Este conceito fundamenta no Brasil o Instituto de Tecnologia Social (ITS) fundado em 2001 que incentiva as iniciativas da sociedade para solucionar e atender suas próprias necessidades do cotidiano. Sendo "[...] o papel do ITS é pesquisar, sistematizar, registrar e divulgar essas experiências" (ITS, 2007, pg 6).

O Guia de Referência aqui proposto foca o portador de deficiência visual. Desta forma, alguns dos princípios do Desenho Universal e da TA serão considerados.

\subsubsection{Projeto para portadores de necessidades especiais: deficiente visual}

Suprir necessidades dos que não enxergam por meio de produtos planejados e de acordo com suas reais condições requer que o projetista esteja ciente de que a deficiência visual do usuário torna o produto diferente para se projetar. Essa diferença advém da constatação de que o DV reconhece e relaciona-se com o ambiente e produtos à sua volta por meio de seus sentidos restantes, isto é, o tato, a audição, o olfato e o paladar. Priorizando o resultado obtido pelo estímulo a cada um destes sentidos o produto poderá ser plenamente utilizado pelo deficiente visual.

Para tanto, entender como o organismo capta e interpreta estímulos externos é necessário (Seção 2.2.5). Já nas seções 2.2.2. 2.2.3. e 2.2.4. é analisada a situação atual de pesquisa e desenvolvimento na área assim como o mercado de produtos comercializados e recomendados para o deficiente visual.

\subsubsection{Produtos para o deficiente visual: pesquisa e desenvolvimento}

Segundo extensa pesquisa realizada pelo ITS em parceria com a Secretaria de Ciência e Tecnologia para a Inclusão Social (SECIS) do Ministério de Ciência e Tecnologia (MCT) a grande maioria das pesquisas realizadas em TA é realizada por instituições acadêmicas com recursos próprios (54,9\%), seguida pelas instituições privadas sem fins lucrativos $(36,6 \%)$. Sendo ressaltada pelo ITS a necessidade de incentivos e políticas de auxílio a produção de patentes neste segmento, pois a produção realizada em ambiente acadêmico fica armazenada na instituição e, na prática, não atinge e beneficia os PNEs, uma vez que as instituições privadas com 
fins lucrativos são a minoria em pesquisa e desenvolvimento relativos a TA $(8,4 \%)$. $\mathrm{Na}$ Tabela 1 estão dispostos dados que demonstram quantitativamente os meios com os quais as iniciativas em TA originam-se.

Tabela 1 - Origem da pesquisa de desenvolvimento em TA no Brasil

\begin{tabular}{c|c|c|c|c|c|c}
\hline $\begin{array}{c}\text { Artigos } \\
\text { Publicados }\end{array}$ & $\begin{array}{c}\text { Inovação em } \\
\text { Produtos }\end{array}$ & $\begin{array}{c}\text { Inovação em } \\
\text { Processos }\end{array}$ & Patentes & $\begin{array}{c}\text { Protótipos } \\
\text { criados }\end{array}$ & $\begin{array}{c}\text { Produtos } \\
\text { Comercializados } \\
\text { com Sucesso }\end{array}$ & $\begin{array}{c}\text { Produtos } \\
\text { Comercializados } \\
\text { sem Sucesso }\end{array}$ \\
\hline 1082 & 243 & 215 & 123 & 8 & 166 & 55 \\
\hline
\end{tabular}

Fonte: Adaptado de ITS (2007)

Ainda, o ITS ressalta a urgência da divulgação maciça do conceito da TA com o objetivo de sensibilizar pesquisadores e principalmente, empresários no desenvolvimento de produtos e outros meios para os PNEs.

Por fim, quanto ao direcionamento da TA a cada tipo de deficiência e com base em dados do IBGE o ITS cita os deficientes visuais como maioria dentre os PNEs e ressalta que o número de pesquisas direcionadas a este grupo em específico não corresponde a este fato, existindo uma carência nesta área.

Analisando as informações de deficiências do IBGE e as áreas de deficiência pesquisadas em TA no Brasil, pode-se notar que as pesquisas não correspondem, na mesma proporção, à demanda existente na sociedade. Enquanto a principal função pesquisada em TA é a muscular, o maior contingente de deficiência na sociedade está concentrado na visão [...] (ITS, 2007, p. 45).

\subsubsection{Produtos o deficiente visual: contexto}

Nota-se, no Brasil, que produtos para DVs são resultado de projetos com baixo investimento e de fabricação com poucos recursos, não ofertando ao deficiente visual brasileiro produtos com grande potencial de auxílio.

Pode-se iniciar esta análise tendo como foco produtos para educação. Para o aprendizado da linguagem Braille, nos EUA, existem produtos que ofertam a possibilidade de combinar os pontos Braille reforçando para o deficiente o conceito de modularidade do sistema (Figura 5), já os produtos brasileiros possuem pontos da linguagem Braille fixos em cartões separados (Figura 6), não reforçando o conceito de combinação de pontos e dificultando a organização de todos os cartões. 
Figura 5 - Produto Americano Braille Doll

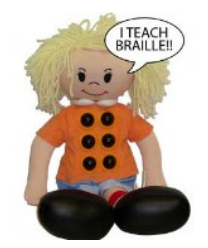

Fonte: Independent Living Aids (2011)
Figura 6 - Produto brasileiro Alfabeto em Braille

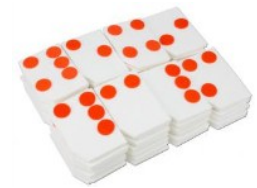

Fonte: CMDV (2011)

Para organização pessoal, nos Estados Unidos, existem produtos como o The Sock Pro (Figura 7) um clip de plástico que tem como função acomodar pares de meias e não permitir que separem durante a lavagem em máquinas de lavar. Não há indícios de fabricantes brasileiros de produtos similares a este.

Figura 7 - Produto americano The Sock Pro

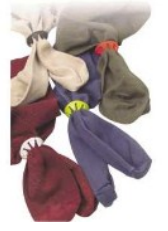

Fonte: Independent Living Aids (2011)

Para a realização de tarefas domésticas e alimentação existem nos Estados Unidos produtos como o Food Bumper (Figura 8), utilizado para prevenir que alimentos caiam para fora do prato. Visto a ausência de produtos como este no Brasil, o DV brasileiro utiliza, por exemplo, recipientes fundos para alimentar-se.

Figura 8 - Produto americano Food Bumper

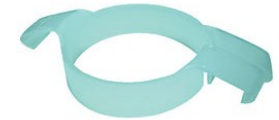

Fonte: Maxi Aids (2011)

Para o segmento da saúde e cuidados pessoais existem, nos Estados Unidos, produtos como o Eye Drop Guide (Figura 9) que é um guia de gotas utilizado para manter o olho do usuário aberto e dirigir a queda de medicamentos em gotas. Não há indícios de fabricantes brasileiros de produtos similares a este. 
Figura 9 - Produto americano Eye Drop Guide

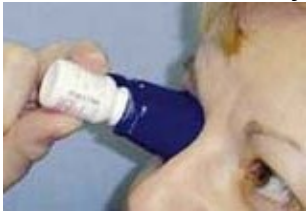

Fonte: LSS Products (2011)

Por meio desta análise pode-se reforçar a afirmativa de que existe certa defasagem ou ausência de produtos brasileiros para o deficiente visual. Assim, há a necessidade e oportunidade de desenvolvimento de produtos com melhores recursos de projeto e fabricação para este segmento em específico.

\subsubsection{Produtos para o deficiente visual: análise}

Para redigir recomendações relevantes ao desenvolvimento de produtos para o DV buscaram-se produtos considerados adequados e recomendados para este usuário. A busca por estes produtos foi conduzida, principalmente, com base em informações disponibilizadas pela American Foundation for the Blind (AFB), organização americana sem fins lucrativos fundada em 1921 ( $A F B, 2011)$. A AFB disponibiliza uma listagem de produtos recomendados para pessoas com deficiência visual divididos em categorias, por função executada ou benefícios proporcionados.

Optou-se por analisar a categoria intitulada Jogos e Atividades, pois segundo Bertolin; Sankari (2006) a utilização de materiais que propiciem o desenvolvimento físico e intelectual do DV são importantes para sua inclusão social. Dentro desta categoria foram escolhidos sete produtos que abrangem um espectro típico de atividades de um DV. Foram identificados a partir da observação de campo cinco termos que concatenam benefícios pretendidos pelo produto ao DV (Quadro 1).

Quadro 1 - Indicadores para análise de um produto para o deficiente visual

\begin{tabular}{|l|l|}
\hline Indicadores & Descrição \\
\hline Orientação & Beneficia a relação entre o deficiente visual e o espaço a seu redor ou objeto \\
\hline Independência & Possibilita o deficiente visual a executar atividades sem o auxílio de outras pessoas \\
\hline Estímulo & Desenvolvimento sensorial ou intelectual por meio de características do produto \\
\hline Segurança & Situações de risco ao deficiente são neutralizadas por características do produto \\
\hline Integração & Característica do produto que promove a socialização do deficiente \\
\hline
\end{tabular}


Um esquema de classificação dos produtos (ver exemplo no Quadro 2) foi idealizado considerando: i) características (sistema sensorial); ii) função; iii) nome: iv) aspecto formal. O Apêndice A contém a análise conduzida.

Quadro 2 - Modelo para avaliação de produtos para o deficiente visual

\begin{tabular}{|c|c|c|c|c|c|c|c|}
\hline 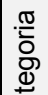 & \multicolumn{2}{|l|}{ Produto } & \multirow{6}{*}{$\begin{array}{c}\text { Descrição } \\
\text { Bola para } \\
\text { prática de } \\
\text { basquete com } \\
\text { sinos duplos } \\
\text { em seu interior } \\
\text { e bip direcional }\end{array}$} & \multicolumn{3}{|c|}{ Elementos do produto que atendem ao deficiente visual } & $\begin{array}{c}\text { Sentido } \\
\text { (princípio) }\end{array}$ \\
\hline \multirow{5}{*}{ 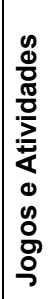 } & \multirow{5}{*}{\multicolumn{2}{|c|}{\begin{tabular}{c|c} 
\\
Fonte: \\
Maxi Aids \\
(2011)
\end{tabular}}} & & Orientação & $\mathrm{X}$ & Os sinos e o bip direcional orientam o DV no espaço & \multirow{5}{*}{$\begin{array}{c}\text { Audição } \\
\text { (sinos e } \\
\text { bip } \\
\text { sonoro) }\end{array}$} \\
\hline & & & & \multicolumn{2}{|l|}{ Independência } & \multirow[b]{2}{*}{ Os sinos estimulam a audição do deficiente } & \\
\hline & & & & Estímulo & \multirow[t]{2}{*}{$\mathrm{X}$} & & \\
\hline & & & & Segurança & & & \\
\hline & & & & Integração & $\mathrm{X}$ & A atividade promove a socialização dos jogadores & \\
\hline
\end{tabular}

Posteriormente, foi conduzida uma análise dos dados extraídos a partir do Quadro 10, contido no Apêndice A. Constatou-se que dos sete produtos, seis endereçavam o sentido do tato e um, a audição. Nenhum dos produtos examinados considera o olfato e o paladar como elementos funcionais.

Quanto ao elemento do produto que atende a determinada necessidade do DV verificou-se que dos seis produtos que consideram o tato, três utilizam-se de relevos, dois da linguagem Braille e um de texturas. O produto direcionado a audição tem seu principio de funcionamento por emissão sonora. O Quadro 3 contém os indicadores e respectiva freqüência observada durante a análise.

Quadro 3 - Indicadores verificados

\begin{tabular}{|c|c|c|c|c|c|c|c|}
\hline Indicadores verificados nos produtos analisados na categoria Jogos e Atividades \\
\hline Produto analisado & $\mathrm{P} 1$ & $\mathrm{P} 2$ & $\mathrm{P} 3$ & $\mathrm{P} 4$ & $\mathrm{P} 5$ & $\mathrm{P} 6$ & $\mathrm{P} 7$ \\
\hline Orientação & $\mathrm{X}$ & $\mathrm{X}$ & & & & & \\
\hline Independência & & & & & $\mathrm{X}$ & $\mathrm{X}$ & $\mathrm{X}$ \\
\hline Estímulo & $\mathrm{X}$ & $\mathrm{X}$ & $\mathrm{X}$ & $\mathrm{X}$ & $\mathrm{X}$ & $\mathrm{X}$ & $\mathrm{X}$ \\
\hline Segurança & & & & & & & \\
\hline Integração & $\mathrm{X}$ & $\mathrm{X}$ & $\mathrm{X}$ & & & $\mathrm{X}$ & $\mathrm{X}$ \\
\hline
\end{tabular}

Pode-se destacar o atendimento ao Indicador "estímulo" por todos os produtos. Também, é importante mencionar que o não atendimento ao critério 
"segurança" não significa que o produto oferece riscos ao usuário mas, sim, que a principal função do produto não é neutralizar situações de risco.

\subsubsection{Portador de deficiência visual: usuário}

Nas seções que seguem apresentam-se características dos sentidos restantes ao deficiente visual e que funcionam como o meio com o qual este consegue interagir com o ambiente.

Para o desenvolvimento do Guia são considerados os sentidos do tato e da audição, pois são os que predominam em frequência de aplicação nos produtos existentes para o deficiente visual em relação ao olfato e paladar (Seção 2.2.4). Como justificativa para o foco exclusivo nestes dois sentidos (tato e audição) podese afirmar que são os que funcionam menos invasivamente ao organismo, se comparados ao olfato e paladar. Portanto, podem ser amplamente aplicáveis em um produto sem maiores implicações ou restrições.

\subsubsection{Tato}

Segundo Guyton et al. (2006) o sentido do tato está presente no maior órgão do corpo humano: a pele. Ainda, segundo este autor, a pele possui grande variedade de receptores sensoriais capazes de detectar sinais e interpretar sensações como o próprio tato, pressão, calor, dor e frio.

Um dos métodos mais utilizados para determinar o limiar de percepção tátil é o método da discriminação de dois pontos. Geralmente, este é determinado por meio de duas agulhas pressionadas levemente ao mesmo tempo sobre determinada região do corpo a certa distância. $O$ indivíduo submetido ao teste relata a capacidade ou não de discriminar os dois pontos em posições diferentes. Segundo Guyton et al. (2006), nas pontas dos dedos um individuo é capaz de distinguir dois pontos separados a distância mínima de 1 a 2 milímetros. Quanto à rugosidade, segundo Santos (2010), o ser humano consegue detectar, em um centímetro quadrado, rugosidade de aproximadamente 50 micromêtros, o que equivale ao diâmetro de um fio de cabelo. 
Estas informações estabelecem limiares importantes a serem utilizados em algumas recomendações do Guia de Referência. Por fim, pode-se mencionar a constatação de Schmidt (1978) que relata que em experimentos que objetivam determinar o limiar para a sensação de estímulos mecânicos na pele, os resultados dependem do método de estimulação utilizado. Ainda, segundo este autor, a partir de experimentos como o da discriminação de dois pontos, pode-se verificar que em pessoas com deficiência visual o limiar de discriminação e sensibilidade não é diferente do que em pessoas sem deficiência.

\subsubsection{Audição}

Segundo Schmidt (1978), o sentido da audição age como instrumento para o DV tomar conhecimento com detalhes do que acontece no ambiente em que está. Segundo este autor, o indivíduo pode saber a movimentação existente ao seu redor, pela simples variação de som detectada. Isto é possível pela localização lateral dos ouvidos e diferença de posição de cada um, que permite que o som chegue a um ouvido antes e a outro depois, sendo percebida essa diferença, por menor que seja.

\subsection{Análise e considerações}

Inicialmente, foram abordados alguns aspectos do macro assunto PDP (Seção 2.1). Assim, pode-se também verificar os princípios da ferramenta a ser desenvolvida, o Guia de Referência (Seção 2.1.1). A situação e contexto da pesquisa e desenvolvimento e dos produtos para este público no Brasil e nos EUA, também foram considerados (Seções 2.2.1, 2.2.2. e 2.2.3).

Considerando o usuário PNE, foram analisados na Seção 2.2 elementos do Desenho Universal (ver aplicação na Seção 3.1) e, posteriormente, focou-se no portador de deficiência visual, suas necessidades e particularidades no modo como se relaciona com produtos (Seção 2.2.4). Por fim, os sentidos do tato e da audição foram estudados com o objetivo de angariar maiores informações a respeito dos limiares de sensibilidade e localização do usuário em questão (seção 2.2.5). 
Desta forma, o desenvolvimento de um Guia de Referência pode contribuir para o projeto e fabricação de produtos que ofereçam suporte as necessidades do deficiente visual bem como estimulem seus sentidos restantes.

\section{GUIA DE REFERÊNCIA PARA O DESENVOLVIMENTO DE PRODUTOS PARA O DEFICIENTE VISUAL}

Nesta seção, são descritas a estruturação e apresentação do Guia de Referência proposto. Define-se como intenção do Guia de Referência a prestação de suporte a projetistas, tanto os novatos (recém-graduados) como os experientes (com três ou mais anos desde a finalização da graduação) que não possuem grande experiência em projetos para o deficiente visual. Este suporte pode ser oferecido pelo guia durante a fase de Projeto Conceitual, uma vez que são poucos os guias dedicados a esta fase (seção 2.1.1) e também devido à natureza das recomendações presente neste, isto é, são recomendações que envolvem características do produto que devem ser inseridas ou examinadas durante as fases mais primárias de concepção, pois são direcionadas a estrutura ou funcionamento geral do produto e não a detalhes e pormenores de fabricação.

\subsection{Estrutura do Guia de Referência}

Após a análise dos produtos recomendados pela $A F B$ (Seção 2.2.3.), desenvolveu-se um mecanismo para estruturar e agrupar recomendações de projeto para esta família de produtos. A estrutura proposta derivada da análise dos Guias de Referência estudados esta contida na Figura 10.

Figura 10 - Estrutura do Guia de Referência

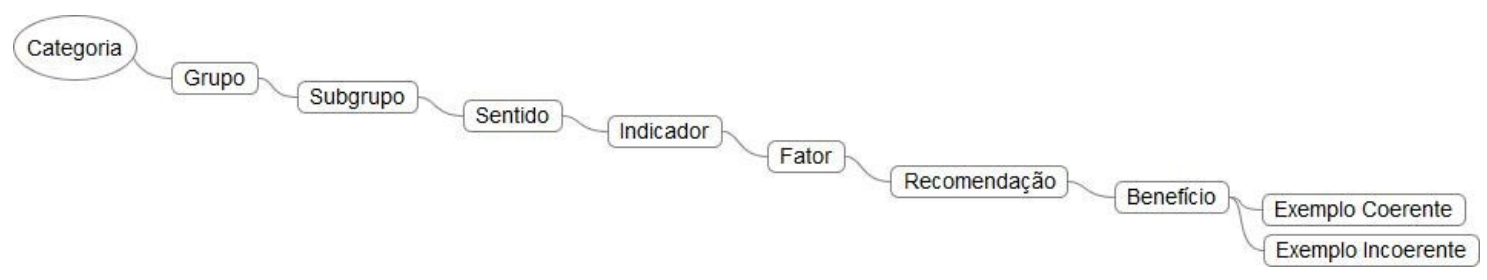


Nesta estrutura são dispostos, em ordem decrescente, termos que agrupam características e pelos quais o projetista poderá direcionar sua pesquisa. No Quadro 4 estão listados e descritos cada nível definido para compor o Guia de Referência.

Quadro 4 - Descrição de cada nível da estrutura do Guia de Referência

\begin{tabular}{|c|c|c|}
\hline Nível & Descrição & Exemplo \\
\hline Categoria & Categoria na qual o produto se encaixa pela função ou benefício. & Jogos e atividades \\
\hline Grupo & Nicho para o qual o produto é direcionado por utilização. & Atividades em grupo / individuais \\
\hline Subgrupo & Nicho para o qual o produto é direcionado por sua função & Jogos de Lógica \\
\hline Sentido & Sentido do sistema sensorial para o qual o produto é direcionado & Audição \\
\hline Indicador & Critério atendido pelo produto caso este acate a recomendação & Orientação (ver Quadro 3) \\
\hline Fator & Elemento que atende a necessidade especifica do DV & Sinalização sonora \\
\hline Recomendação & $\begin{array}{l}\text { Descrição de qual característica o produto tem de possuir total ou } \\
\text { parcialmente para atender ao fator, indicador, sentido, subgrupo e } \\
\text { grupo a qual foi direcionado. Cada recomendação possui um } \\
\text { código de identificação, caso exista recorrência }\end{array}$ & $\begin{array}{l}\text { R1 - Utilizar sons simples e de fácil } \\
\text { identificação: } \\
\text { mecânicos por meio da movimentação, } \\
\text { atrito ou choque de componentes }\end{array}$ \\
\hline Benefícios & $\begin{array}{l}\text { Por meio de tópicos, são listados os benefícios gerados para o } \\
\text { usuário portador de deficiência visual por meio do produto que } \\
\text { possui como característica a aplicação da recomendação }\end{array}$ & $\begin{array}{l}\text { Localiza o DV no ambiente estimula a } \\
\text { audição, permite associações de } \\
\text { diferentes partes do produto }\end{array}$ \\
\hline $\begin{array}{l}\text { Exemplo } \\
\text { coerente }\end{array}$ & $\begin{array}{l}\text { llustração de como a recomendação pode ser facilmente aplicada } \\
\text { em produtos do grupo em questão }\end{array}$ & Dado sonoro \\
\hline $\begin{array}{l}\text { Exemplo } \\
\text { incoerente }\end{array}$ & $\begin{array}{l}\text { Imagem de um produto comercializado e que exemplifica o não } \\
\text { atendimento a recomendação em questão }\end{array}$ & Fonte: Bengala Branca (2011) \\
\hline
\end{tabular}

Similarmente a Bralla (1999), o Guia de Referência desenvolvido disponibiliza de forma didática um exemplo coerente e outro incoerente para com cada recomendação. Seguindo a mesma linha de Baxter (2000) e Pahl (2005) o Guia de Referência demonstra exemplos reais. Estes exemplos podem ser visualizados no último nível de cada recomendação e são úteis para casos onde o projetista possui dúvidas sobre como e quando aplicar certa recomendação. Com a intenção de facilitar o processo de aplicação das recomendações de projeto, o Guia de Referência proposto funciona como um check list, enumerando regras de desenvolvimento, conforme modelo APQP adotado pela indústria automobilística 
(FORD, 2003). Conforme o conceito do modelo de Ashby (1992), a estrutura do guia proposto é baseada no poder de escolha e da combinação de variáveis (direcionando as recomendações conforme o produto a ser desenvolvido) adotando uma postura flexível e deixando a cargo do time de projeto a melhor utilização do guia conforme a situação.

A partir da estruturação do guia, pode-se iniciar a descrição das recomendações para o desenvolvimento de produtos do grupo "Jogos e Atividades". As recomendações foram geradas a partir: i. das boas características presentes nos produtos analisados; ii. da experiência dos autores no desenvolvimento deste tipo de produto. iii. de dados obtidos por meio de referenciais teóricos.

Pode-se mencionar a aplicação nas recomendações de conceitos derivados do Desenho Universal como: i. uso equitativo (e.g: R8 que sugere inscrições em Braille sinalizando informações importantes ao deficiente visual sobre o produto); ii. uso intuitivo (e.g: R2 e R3 que sugerem o uso da diferença de relevo ou de texturas para sinalizar partes ou funções diferentes do produto); iii. Tolerância ao erro (e.g: R5 que sugere superfícies planas na base do produto, agregando estabilidade e evitando deslocamentos que o DV pode não perceber).

\subsection{Guia de Referência: proposta}

Após a estruturação, organização e preenchimento de dados, o Guia de Referência possui a configuração conforme Figura 11.

Pode-se visualizar a segmentação de grupos e subgrupos, conforme o contexto do produto a ser desenvolvido e posteriormente, quanto a sua utilidade ou função. Também, pode-se notar que algumas recomendações podem ser repetidas em subgrupos diferentes, apenas tendo seu exemplo modificado de acordo com o contexto de utilização.

Encontra-se no Apêndice B, o conjunto das recomendações R1 a R4 do Guia de Referência proposto. O Guia completo poderá ser fornecido mediante solicitação aos autores. 
Figura 11 - Excerto do Guia de Referência

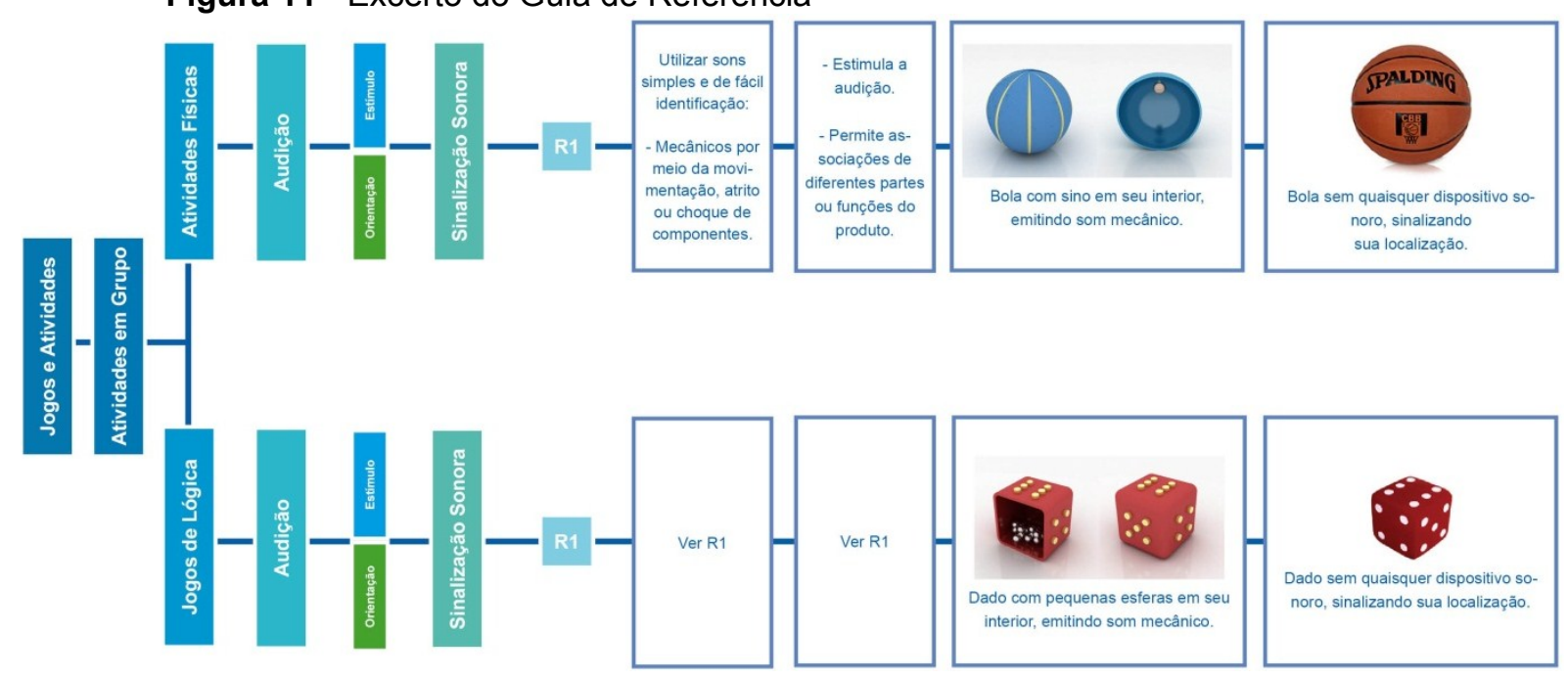

\section{APLICAÇÕES DO GUIA DE REFERÊNCIA PROPOSTO}

Uma vez o Guia de Referência estruturado e organizado (com recomendações e exemplificações) pode-se iniciar a fase de aplicações. Esta etapa tem como objetivo a verificação da aderência das verificações contidas no guia para com produtos recomendados e comercializados atualmente para o portador de deficiência visual (Seção 4.2.). Também, pode-se observar se este é aplicável ao público-alvo a que se destina e à fase de projeto a que é direcionado.

\subsection{Aplicação descritiva}

O objetivo desta seção é apresentar a consistência do Guia de Referência apresentado na Seção 3. Para tanto, são assumidos os pressupostos: i. Análise de um produto para DVs utilizando-se do Guia de Referência, na categoria Jogos e Atividades como referência; ii. Seleção de um produto reconhecidamente recomendado para a utilização de portadores de deficiência visual; iii. Identificação no Guia de Referência de características do produto analisado; iv. Classificação do atendimento das características mapeadas em total (atende), parcial (atende parcialmente), negativo (não atende) e sem aplicação; v. Análise dos dados obtidos.

A análise ocorreu pela verificação do nível de atendimento das características deste produto as recomendações da categoria Jogos e Atividades. O produto 
escolhido é o Jogo da Memória Tátil (Quadro 5), da fabricante brasileira de brinquedos Grow Jogos e Brinquedos S.A., atuante no mercado desde 1972. A escolha deste jogo aconteceu pelo reconhecimento da Fundação Dorina Nowill para Cegos (PALAVRA EDITORA E ARTE, 2006) como sendo este um produto que contribui definitivamente como um agente do desenvolvimento sensorial e intelectual dos deficientes visuais. Este reconhecimento é atestado pela assinatura da fundação que o produto tem em sua embalagem, sendo incluso em um grupo de produtos da chamada Coleção Dorina Nowill.

Quadro 5 - Descrição do produto selecionado para análise

\begin{tabular}{|c|c|c|}
\hline PRODUTO & \multicolumn{2}{|r|}{ DESCRIÇÃO } \\
\hline & Produto & Brinquedo, Jogo da Memória Tátil \\
\hline & Faixa Etária & A partir de cinco anos \\
\hline & Aplicação & Individual ou em dupla \\
\hline Fonte: Ilha do Tabuleiro (2007) & Itens & $\begin{array}{l}\text { - Um tabuleiro } \\
\text { - Uma venda } \\
\text { - Nove pares de quadrados (cartões táteis) com as } \\
\text { texturas: papel cartão ondulado, E.V.A., couro ecológico, } \\
\text { papel reciclado, lixa, espuma, E.V.A. granulado, juta e } \\
\text { vamurça }\end{array}$ \\
\hline 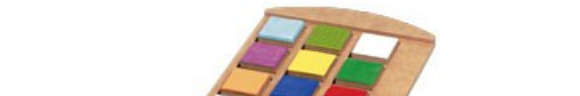 & $\begin{array}{c}\text { Habilidades } \\
\text { desenvolvidas }\end{array}$ & $\begin{array}{l}\text { Estímulo à memória, atenção e concentração, } \\
\text { desenvolvimento tátil, orientação espacial }\end{array}$ \\
\hline Fonte: Palavra Editora e Arte (2006) & Funcionamento & $\begin{array}{l}\text { - Deve-se embaralhar os cartões táteis e posicioná-los de } \\
\text { costas no tabuleiro. } \\
\text { - Jogadores sem deficiência visual devem utilizar a } \\
\text { venda. } \\
\text { - Conforme um jogo da memória convencional, deve-se } \\
\text { achar os pares correspondentes. }\end{array}$ \\
\hline
\end{tabular}

A avaliação do produto ocorreu por meio da verificação do nível de atendimento das recomendações (Quadro 6), listando aquelas necessárias pelo grupo e subgrupo no qual o produto pode ser enquadrado (R1 a R9 disponíveis no Guia completo).

A partir da análise conduzida pode-se observar que cinco (R2, R3, R5, R6 e R7) das nove recomendações são completamente mapeáveis no produto examinado. Além disto, uma recomendação é parcialmente verificada (R4). Desta forma, pode-se inferir que, se o Guia de Referência estivesse à disposição da equipe de projeto do Jogo da Memória Tátil, poderiam ser aplicadas mais três das 
recomendações presentes no Guia de Referência em questão e que na configuração analisada do produto não são atendidas (R8) ou não são aplicáveis (R1 e R9).

\begin{tabular}{|c|c|c|c|c|c|c|}
\hline & $\begin{array}{c}\text { Recomendação } \\
\text { (A = Atende }, A P=\text { Atende Parcialmente, } \\
\text { NA = Não Atende, } A S=\text { Sem Aplicação) }\end{array}$ & A & AP & $\begin{array}{l}\mathrm{N} \\
\mathrm{A}\end{array}$ & SA & $\begin{array}{l}\text { Característica do produto coerente com a } \\
\text { recomendação }\end{array}$ \\
\hline R1 & $\begin{array}{l}\text { Utilizar sons simples e de fácil identificação: } \\
\text { - Mecânicos por meio da movimentação, atrito ou } \\
\text { choque de componentes. }\end{array}$ & & & & $\mathrm{x}$ & O produto não possui dispositivos sonoros. \\
\hline R2 & $\begin{array}{l}\text { Utilizar diferenças de relevo (variando entre alto e } \\
\text { baixo-relevo) de modo exista uma diferença de no } \\
\text { mínimo } 5 \mathrm{~mm} \text {. }\end{array}$ & $\mathrm{X}$ & & & & $\begin{array}{l}\text { No tabuleiro, o produto possui diferença de } \\
\text { relevo com mais de } 5 \mathrm{~mm} \text {. }\end{array}$ \\
\hline R3 & $\begin{array}{l}\text { Utilizar texturas diferentes, alternando padrões que } \\
\text { contenham diferença de rugosidade de no mínimo } 50 \\
\text { micrometros. }\end{array}$ & $x$ & & & & $\begin{array}{l}\text { Os cartões táteis possuem diferença de } \\
\text { texturas. }\end{array}$ \\
\hline R4 & $\begin{array}{l}\text { Utilizar materiais explorando três aspectos: densidade, } \\
\text { temperatura ambiente e acabamento superficial. }\end{array}$ & & $x$ & & & $\begin{array}{l}\text { Com exceção das texturas, o restante do } \\
\text { produto é produzido madeira. }\end{array}$ \\
\hline R5 & $\begin{array}{l}\text { Utilizar superfícies planas na interface do produto com } \\
\qquad \text { o ambiente. }\end{array}$ & $x$ & & & & $\begin{array}{c}\text { O tabuleiro e cartões táteis possuem } \\
\text { superfície plana para apoio e armazenamento. }\end{array}$ \\
\hline R6 & $\begin{array}{c}\text { Caso a R5 não seja aplicável, planejar compartimentos } \\
\text { ou bases para o armazenamento dos componentes } \\
\text { formalmente instáveis. }\end{array}$ & $x$ & & & & $\begin{array}{c}\text { Mesmo possuindo superfície plana, os cartões } \\
\text { táteis possuem locais específicos para } \\
\text { armazenamento. }\end{array}$ \\
\hline R7 & $\begin{array}{l}\text { Dimensionar os componentes e partes do produto de } \\
\text { modo que sejam maiores do que um cubo } \\
\text { representativo com arestas de } 5 \mathrm{~mm} \text {. }\end{array}$ & $x$ & & & & $\begin{array}{l}\text { Todos os componentes possuem dimensões } \\
\text { maiores que um cubo de } 5 \mathrm{~mm} \text {. }\end{array}$ \\
\hline $\mathrm{R} 8$ & $\begin{array}{l}\text { Sinalizar informações importantes em produtos por } \\
\text { meio da linguagem Braille. }\end{array}$ & & & $x$ & & $\begin{array}{l}\text { O produto e a embalagem não possuem } \\
\text { sinalização Braille. }\end{array}$ \\
\hline R9 & $\begin{array}{c}\text { Sinalizações em Braille devem estar distantes pelo } \\
\text { menos duas vezes seu diâmetro de demais relevos do } \\
\text { produto com que possam ser confundidos (com formato } \\
\text { circular e configurados de forma alinhada). }\end{array}$ & & & & $x$ & $\begin{array}{l}\text { O produto e a embalagem não possuem } \\
\text { sinalização Braille. }\end{array}$ \\
\hline
\end{tabular}

\subsection{Aplicação experimental}

O objetivo desta seção é apresentar a aplicabilidade do Guia de Referência descrito na Seção 3. Para tanto, são assumidos os pressupostos: i. elaboração de um enunciado definindo parâmetros de projeto; ii. mapeamento das características ideais da concepção a ser gerada; iii. seleção de seis projetistas com níveis 
diferenciados de experiência; iv. divisão destes em três grupos de dois componentes: projetistas com nível variado de experiência, projetistas novatos (recém-formados) e projetistas experientes (com mais de três anos de formação); v. definição de dois grupos para trabalhar com o auxilio do Guia de Referência e de um grupo para trabalhar sem o auxílio do Guia de Referência;

Buscou-se a realização desta aplicação experimental junto a desenvolvedores de produto com níveis de experiência variados e que tiveram pouco contato com o tema "deficiência visual". Para cada desenvolvedor de produto foi proposto o enunciado conforme Quadro 7:

Quadro 7 - Enunciado proposto aos projetistas

\begin{tabular}{|l|l|}
\hline \multicolumn{2}{|c|}{ PROPOSTA - CONCEPÇÃO DE UM PRODUTO PARA O DEFICIENTE VISUAL } \\
\hline PRODUTO & Jogo da memória \\
\hline PÚBLICO & Novo deficiente visual (crianças e adultos que adquiram deficiência recentemente) \\
\hline OBJETIVO DO PRODUTO & Desenvolver social, intelectual e sensorialmente o deficiente visual. \\
\hline INSTRUÇÕES & $\begin{array}{l}\text { - Utilize um ou mais dos seguintes meios de representação: } \\
\text { - breve descrição por escrito / desenho simples / por meio de tópicos }\end{array}$ \\
\hline
\end{tabular}

O objetivo deste enunciado é identificar como cada desenvolvedor de produto trabalha com a questão proposta, com o auxílio do Guia de Referência e, também, sem o auxílio deste. No Quadro 8, pode-se observar a divisão dos grupos e o contexto de trabalho de cada um.

Quadro 8 - Descritivo dos grupos divididos para a realização do experimento

\begin{tabular}{|l|l|}
\hline GRUPO 1 & Dois projetistas (P1 e P2) trabalhando sem o auxílio do Guia de Referência. \\
\hline GRUPO 2 & Dois projetistas recém-formados (P3 e P4) com o auxílio do Guia de Referência. \\
\hline GRUPO 3 & Dois projetistas experientes (P5 e P6) com o auxílio do Guia de Referência. \\
\hline
\end{tabular}

O experimento foi conduzido de forma individual, devidamente acompanhado e cronometrado, sendo registrado o número de consultas ao Guia de Referência (quando utilizado). Posteriormente, uma análise da concepção gerada por cada desenvolvedor de produto foi realizada. No Quadro 9, pode-se visualizar a concepção de cada projetista. 


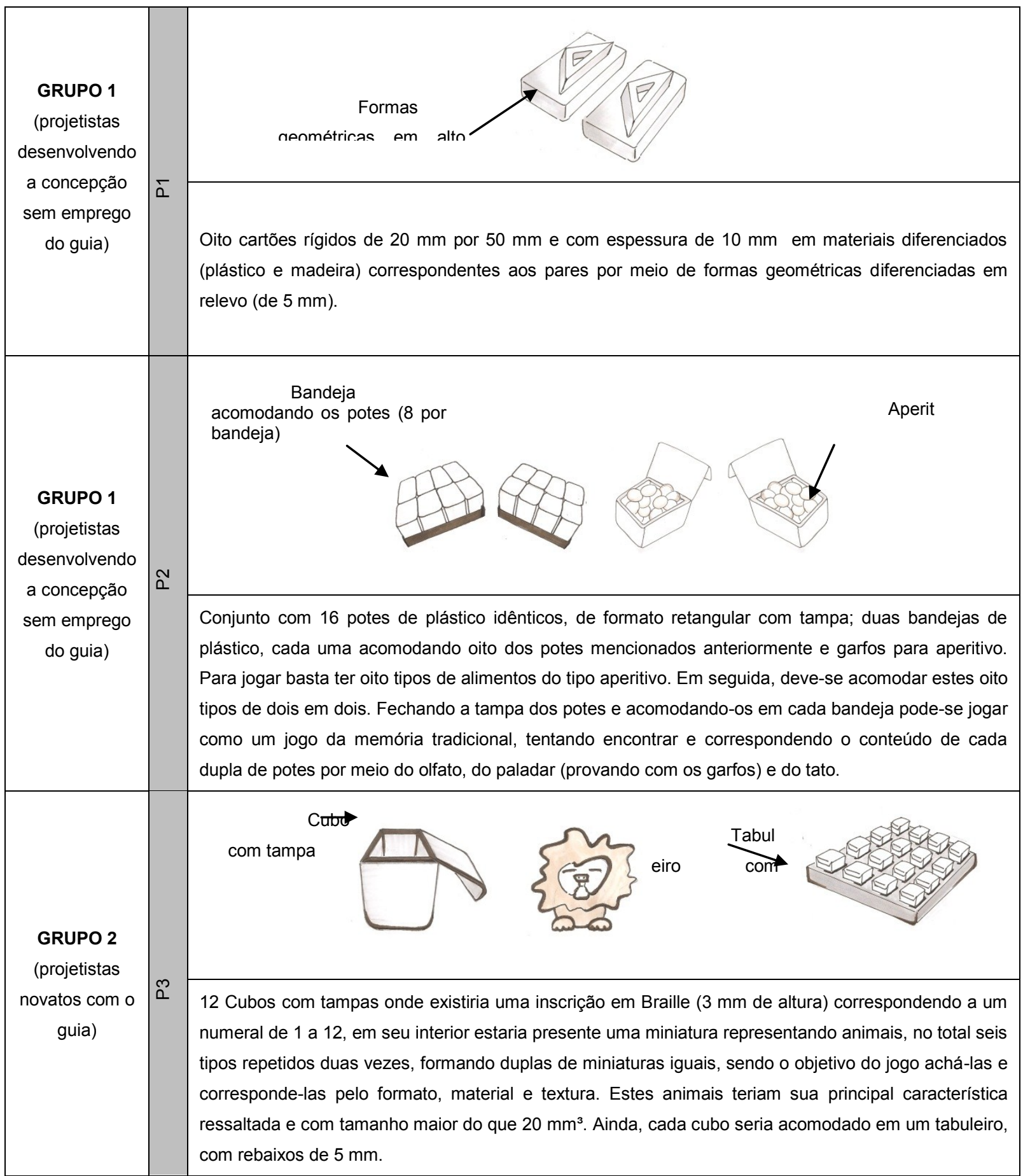

Revista Produção Online, Florianópolis, SC, v.13, n. 1, p. 257-289, jan./mar. 2013. 


\begin{tabular}{|c|c|c|}
\hline & \multirow[t]{2}{*}{ ¿ } & $\begin{array}{cc}\text { Pirâmides } & \text { Cubo } \\
\text { correspondentes } & \text { formado pels }\end{array}$ \\
\hline & & $\begin{array}{l}\text { O produto seria formado por pirâmides encaixadas por meio de uma referência em Braille }(5 \mathrm{~mm}) \text { e } \\
\text { profundidade (de } 1 \mathrm{a} 4 \mathrm{~mm} \text { ), sendo compatíveis as pirâmides com a mesma textura. Ao total, seriam } \\
\text { oito pirâmides formando quatro cubos com texturas diferentes. Se encaixados estes cubos formariam } \\
\text { outro maior. }\end{array}$ \\
\hline \multirow{4}{*}{$\begin{array}{l}\text { GRUPO } 3 \\
\text { (projetistas } \\
\text { experientes } \\
\text { com o guia) }\end{array}$} & \multirow{2}{*}{10} & 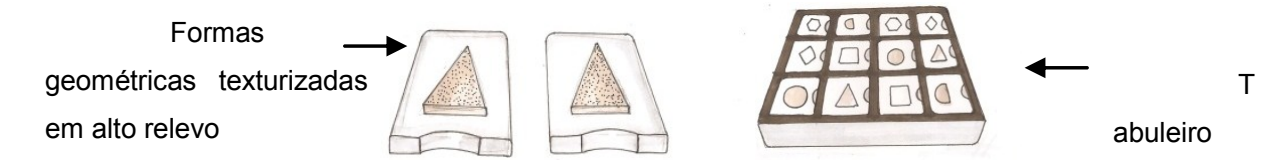 \\
\hline & & $\begin{array}{l}12 \text { cartões rígidos (com } 10 \mathrm{~mm} \text { de espessura) correspondente em pares com seis formas geométricas } \\
\text { diferentes em alto ou baixo relevo (com profundidade ou altura de } 5 \mathrm{~mm} \text { ). Cada peça seria acomodada } \\
\text { em um tabuleiro com } 12 \text { rebaixos (com } 5 \mathrm{~mm} \text { ) que em suas bordas teria referenciais em Braille } \\
\text { funcionando como coordenadas. Cada forma geométrica teria arestas maiores do que } 20 \mathrm{~mm} \text {. }\end{array}$ \\
\hline & & $\begin{array}{l}\text { Inscrições com } \\
\text { alto e baixo relevo, formando } \\
\text { os encaixes necessários }\end{array}$ \\
\hline & & $\begin{array}{l}12 \text { cartões rígidos em materiais diferenciados correspondentes aos pares. Em cada cartão, seriam } \\
\text { alternados alto e baixo relevo com formatos diferenciados com } 5 \mathrm{~mm} \text { de altura ou profundidade. O } \\
\text { objetivo seria encontrar os cartões correspondentes e encaixá-los formando um bloco. }\end{array}$ \\
\hline
\end{tabular}

Para verificar as características de cada ideia concebida foi elaborado um conjunto de características ideais que o produto Jogo da Memória deve possuir para atender plenamente a utilização de um ou mais DVs. Estas características foram extraídas do Guia proposto bem como do produto "Jogo da Memória Tátil" analisado na Seção 4.1. Na Tabela 2, pode-se verificar a adequação das concepções propostas a características elementares para produtos destinados ao DV. 
Tabela 2 - Avaliação das concepções geradas

\begin{tabular}{|c|c|c|c|c|c|c|}
\hline \multirow{2}{*}{$\begin{array}{l}\text { Boa característica } \\
\qquad(\mathbf{A}=\text { Atende })\end{array}$} & \multicolumn{2}{|c|}{ Grupo 1} & \multicolumn{2}{|c|}{ Grupo 2} & \multicolumn{2}{|c|}{ Grupo 3} \\
\hline & P1 & P2 & P3 & P4 & P5 & P6 \\
\hline $\begin{array}{l}\text { Executar plenamente a função de “Jogo da Memória” tendo em vista as } \\
\qquad \text { limitações do deficiente visual. }\end{array}$ & A & - & A & A & A & A \\
\hline $\begin{array}{l}\text { Utilizar sons simples e de fácil identificação: } \\
\text { Mecânicos por meio da movimentação de componentes. }\end{array}$ & - & - & - & - & - & - \\
\hline $\begin{array}{l}\text { Utilizar diferenças de relevo de modo que o entre um plano e outro exista } \\
\qquad \text { uma diferença de no mínimo } 5 \mathrm{~mm}\end{array}$ & A & $A$ & $A$ & A & A & A \\
\hline $\begin{array}{l}\text { Utilizar texturas diferentes, alternando padrões que contenham diferença } \\
\text { de rugosidade de no mínimo } 50 \text { micrometros. }\end{array}$ & - & - & A & A & A & - \\
\hline $\begin{array}{l}\text { Utilizar materiais explorando três aspectos: densidade, temperatura } \\
\qquad \text { ambiente e acabamento superficial. }\end{array}$ & A & - & A & - & - & A \\
\hline Utilizar superfícies planas na interface do produto com o ambiente. & A & A & A & A & A & A \\
\hline $\begin{array}{l}\text { Planejar compartimentos ou bases para o armazenamento dos } \\
\text { componentes formalmente instáveis. }\end{array}$ & - & A & A & - & A & - \\
\hline $\begin{array}{l}\text { Dimensionar os componentes e partes do produto de modo que sejam } \\
\text { maiores do que um cubo representativo (arestas }=5 \mathrm{~mm} \text { ). }\end{array}$ & A & A & A & A & A & A \\
\hline Sinalizar informações importantes em produtos por meio do Braille & - & - & A & A & A & - \\
\hline $\begin{array}{l}\text { Sinalizações em Braille devem estar distantes pelo menos duas vezes } \\
\text { seu diâmetro de demais relevos. }\end{array}$ & - & - & A & A & A & - \\
\hline TOTAL DE BOAS CARACTERÍSTICAS ATENDIDAS (A) & 5 & 4 & 9 & 7 & 8 & 5 \\
\hline
\end{tabular}

$\mathrm{Na}$ Tabela 3, podem-se verificar os resultados do experimento.

Tabela 3 - Comparação dos resultados e dados obtidos durante o experimento

\begin{tabular}{cccccccc}
\hline & \multicolumn{3}{c}{ Grupo 1 } & \multicolumn{2}{c}{ Grupo 2 } & \multicolumn{2}{c}{ Grupo 3 } \\
\cline { 2 - 7 } & $\mathrm{P} 1$ & $\mathrm{P} 2$ & $\mathrm{P} 3$ & $\mathrm{P} 4$ & $\mathrm{P} 5$ & $\mathrm{P} 6$ \\
\hline Atendimento as recomendações direcionadas & $50 \%$ & $40 \%$ & $90 \%$ & $70 \%$ & $80 \%$ & $50 \%$ \\
Tempo necessário para propor a solução & $18 \mathrm{~min}$ & $40 \mathrm{~min}$ & $32 \mathrm{~min}$ & $34 \mathrm{~min}$ & $35 \mathrm{~min}$ & $40 \mathrm{~min}$ \\
Número de consultas ao Guia de Referência & Não aplicável & Não aplicável & 4 & 3 & 2 & 3 \\
\hline
\end{tabular}

\subsection{Resultados}

A partir da aplicação descritiva realizada e, também, da aplicação prática, pode-se afirmar que o Guia de Referência desenvolvido e descrito no presente artigo é aplicável no desenvolvimento de produtos da categoria "Jogos e Atividades" para o deficiente visual. 
O Guia de Referência produz um mapeamento coerente para com um produto fortemente recomendado para o DV, o Jogo da Memória Tátil da fabricante Grow e que leva a assinatura da Fundação Dorina Nowill para Cegos. Isto ocorre porque o produto atende cinco das nove recomendações direcionadas a seu segmento e que, ainda, com pequenas modificações poderia atender mais quatro recomendações, totalizando todas as recomendações direcionadas.

A aplicação experimental reforça a ideia de que o Guia é aplicável a projetistas com níveis variados de experiência, uma vez que os grupos que tiveram seu auxílio durante o experimento obtiveram resultados médios melhores do que os que não tiveram: i. grupo um com $45 \%$; ii. grupo dois com $80 \%$; iii. grupo três com $65 \%$.

O tempo médio de trabalho de cada grupo foi: i. de 56 minutos para o Grupo 1, composto por projetistas que não utilizaram o guia; ii. 33 minutos para o Grupo 2 , composto por projetistas novatos com o auxílio do guia; iii. 37,5 minutos para o Grupo 3, composto por projetistas experientes com o auxílio do guia. Nota-se que o tempo do grupo que não utilizou o Guia é maior do que o dos grupos que utilizaram.

Por fim, quanto ao número de consultas ao guia (para os grupos que o utilizaram), constatou-se que o número de consultas do grupo de projetistas novatos (3,5 consultas) é maior em média do que o número de consultas (2,5 consultas) do grupo de projetistas experientes. Este resultado comprova que o Guia cumpre a função de suporte a projetistas novatos. Como consequência deste número médio maior de consultas, verifica-se o melhor resultado (com relação à quantidade de "boas características" atendidas) obtido pelos projetistas novatos (Tabela 3).

\section{CONSIDERAÇÕES FINAIS}

Os portadores de deficiência visual constituem importante parcela da população brasileira. Focando neste grupo específico de PNE, constatou-se que os produtos brasileiros para o DV são adaptações simplificadas e que não atendem plenamente suas necessidades. Ainda, constatou-se que a maioria da pesquisa e desenvolvimento geradas no Brasil em tecnologia voltada ao DV dificilmente ultrapassa o ambiente acadêmico (ITS,2007). Extensiva análise da literatura não 
indicou a existência de recursos que auxiliem os projetistas a desenvolver produtos para esta categoria de usuários. Um Guia de Referência como recurso auxiliar de projeto foi proposto, sendo estruturado em grupos de aplicação que desmembrados em subgrupos, auxiliam o projetista a encontrar a recomendação correta e mais adequada. A recomendação é descrita e exemplos de aplicação são disponibilizados. Uma aplicação descritiva caracteriza o funcionamento do Guia e sua compatibilidade para com o mercado de produtos para o DV. Em seguida o Guia foi testado em uma aplicação experimental, envolvendo projetistas com diferentes níveis de experiência.

Após análise dos resultados obtidos pela aplicação descritiva e experimental, foi constatado que o Guia proposto atende o objetivo inicial (Seção 1). Assim, podese afirmar que o Guia é coerente para com um produto reconhecidamente recomendado para o DV (Seção 4.1); também, que é aplicável e oferece suporte efetivo para o público-alvo o qual é destinado (projetistas com variados níveis de experiência em projeto e sem experiência prévia com o assunto deficiência visual) e a fase de Projeto Conceitual, como se pode verificar na Seção 4.2.

Verifica-se que ao utilizar o Guia, existe um aumento na qualidade de concepções de produtos geradas por projetistas novatos, comparativamente a projetistas experientes, uma vez que o resultado obtido pelos novatos foi melhor em média do que o obtido pelos experientes (verificar afirmativas nas Seções 4.2 e 4.3).

Com relação ao tempo de projeto, a utilização do Guia de Referência torna mais rápido o processo de concepção de um produto para o DV, oferecendo ao projetista boas características e parâmetros. Assim, o tempo para a geração de alternativas ou até mesmo seleção destas, diminui (Seções 4.2 e 4.3).

Portanto, conclui-se o presente artigo apresenta uma proposta de Guia de Referência plenamente aplicável a fase de Projeto Conceitual e que possibilita efetivo suporte para projetistas com variados níveis de experiência. 


\section{REFERÊNCIAS}

ALVARENGA, Flávia Bonilha. Uma abordagem metodológica para o projeto de produtos inclusivos. Tese (Doutorado) - Universidade Estadual de Campinas, Faculdade de Engenharia Mecânica. Campinas, 2006.

AMERICAN FOUNDATION FOR THE BLIND. 2011. Disponível em: <http://www.afb.org/>. Acesso em: 17 jun. 2011.

ASHBY, Michael F. Materials selection in mechanical design. Oxford: Pergamon Press, 1992.

BAXTER, Mike. Projeto de produto: guia prático para o design de novos produtos. 2 ed. São Paulo: Blucher, 2000.

BENGALA BRANCA. 2011. Disponível em: <http://www.bengalabranca.com.br>. Acesso em: 24 jul. 2011, 12:42.

BERNARDI, Núbia; KOWALTOWSKI, Doris C. C. K. Reflexões sobre a aplicação dos conceitos do desenho universal no processo de projeto de arquitetura. In:

ENCAC - ENLACAC, 6 e 4,. 2005, Maceió. Anais... Maceió: ANTAC - Associação Nacional de Tecnologia do Ambiente Construído, 2005. p. 157-158. Disponível em: < http://www.fec.unicamp.br/ doris/pt/artigos/con html/pdf/Encac2005 desenho unive rsal.pdf>. Acesso em: 28 ago. 2011.

BERTOLIN, Daiana Espíndula; SANKARI, Aline Mendes. Sensibilidade além dos olhos. São Paulo: Annablume, 2006.

BERSCH, Rita. Introdução à Tecnologia Assistiva. CEDI - Centro especializado em desenvolvimento infantil. Porto Alegre, 2008. Disponível em:

http://www.assistiva.com.br/Introducao\%20TA\%20Rita\%20Bersch.pdf. Acesso em: 20 jan. 2012.

BRALLA, James G. (Ed.) Design for manufacturability handbook. 2 ed. Boston: McGraw-Hill, 1999.

CALLISTER, William D. Jr. Ciência e engenharia de materiais: uma introdução. 5 ed. Rio de Janeiro: LTC, 2002.

CMDV, 2011. Disponível em: <http://www.artigosespeciais.com.br>. Acesso em: 24 jul. 2011.

CZIULIK, Carlos; PRINCIVAL, Darlan. Set of guidelines for conceptual design focusing on electrical safety of refrigerators. Product: Management \&

Development. São Carlos, v. 6, n.2, p. 99 - 113, dez. 2008. 
DONG et al. UK and US industrial perspectives on inclusive design proceedings.

INCLUDE 2003, 2nd International Conference. London, v.10, p. 406-409, 2003.

FORD. Planejamento avançado da qualidade do produto (APQP) - manual para relatório de status, ago. 2003

FUNDAÇÃO DORINA NOWILL PARA CEGOS. Legislação. São Paulo, 2011. Disponível em: <http://www.fundacaodorina.org.br/deficiencia-visual/>. Acesso em: 09 ago. 2011.

GUYTON, Arthur C.; Hall, J. E. Tratado de fisiologia médica. 11. ed. Rio de Janeiro: Elsevier, 2006.

ILHA DO TABULEIRO, 2007. Disponível em: < http://www.llhadotabuleiro.com.br/jogos/memoria-tactil>. Acesso em: 24 jul. 2011.

INDEPENDENT LIVING AIDS, 2011. Disponível em:

<http://www.independentliving.com>. Acesso em: 24 jul. 2011, 11:47.

INSTITUTO BRASILEIRO DE GEOGRAFIA E ESTATÍSTICA. Censo Demográfico - 2000: tabulação avançada: resultados preliminares da amostra. Rio de Janeiro, mai. 2002. Disponível em:

http://www.ibge.gov.br/home/presidencia/noticias/08052002tabulacao.shtm>. Acesso em: 28 ago. 2011.

ITS. Pesquisa Nacional de Tecnologia Assistiva. Revista Conhecimento - Ponte para a Vida, São Paulo, n.1-2, p.42-49, mar. 2007. Disponível em:

$<$ http://www.assistiva.org.br/sites/default/files/revista its numeros1 e 2.pdf>.

Acesso em: 20 jan. 2012.

LSS PRODUCTS. 2011. Disponível em: <http://www.Issproducts.com>. Acesso em: 24 jul. 2011, 12:15.

MAXI AIDS. 2011. Disponível em: <http://www.maxiaids.com>. Acesso em: 24 jul. 2011, 12:34.

PAHL, Gerard et al. Projeto na engenharia: fundamentos do desenvolvimento eficaz de produtos, métodos e aplicações. São Paulo: E. Blücher, 2005.

PALAVRA EDITORA E ARTE, 2006. Disponível em:

$<$ http://www. palavraeditoraearte.com.br/noticias int.php?new id=148\&edicao id=8>. Acesso em: 09 ago. 2011.

PUGH, Stuart. Total Design. integrated methods for successful product engineering. Wokingham: Addison-Wesley Publishing Company, 1991.

QUANTUM RLV. 2011. Disponível em: <http://www.quantumrlv.com.au/Jot-aDot.html>. Acesso em: 24 jul. 2011, 19:21. 
ROZENFELD, Henrique et al. Gestão de desenvolvimento de produtos: uma referência para a melhoria do processo. São Paulo: Saraiva, 2006.

SALGADO et al. Modelos de Referência para desenvolvimento de produtos:

Classificação, análise e sugestões para pesquisas futuras. Revista Produção

Online, Florianópolis, v.10, n.4, p 886 - 911, dez. 2010.

SANTOS, Carlos Alberto dos. Segunda pele. Revista Ciência Hoje. Rio de Janeiro, set. 2010. Disponível em: <http://cienciahoje.uol.com.br/colunas/do-laboratorio-paraa-fabrica/segunda-pele>. Acesso em: 07 ago. 2011.

SCHMIDT, Robert F. (Ed.) Fundamentals of sensory physiology. 3 ed. Berlin: Springer-Verlag, 1978.

WORLD HEALTH ORGANIZATION. Nota descriptiva n²82. Genebra, Abr. 2011 Disponível em: <http://www.who.int/mediacentre/factsheets/fs282/es/>. Acesso em: 28 ago. 2011.

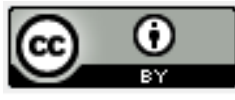

Artigo recebido em 31/10/2011 e aceito para publicação em 07/05/2012. 


\title{
APÊDICE A - ANÁLISE DE PRODUTOS PARA O DEFICIENTE VISUAL
}

\author{
O quadro 10 apresenta os produtos examinados com o respectivo
} enquadramento, conforme proposto no Quadro 2.

Quadro 10 - Modelo para análise de produtos para o deficiente visual

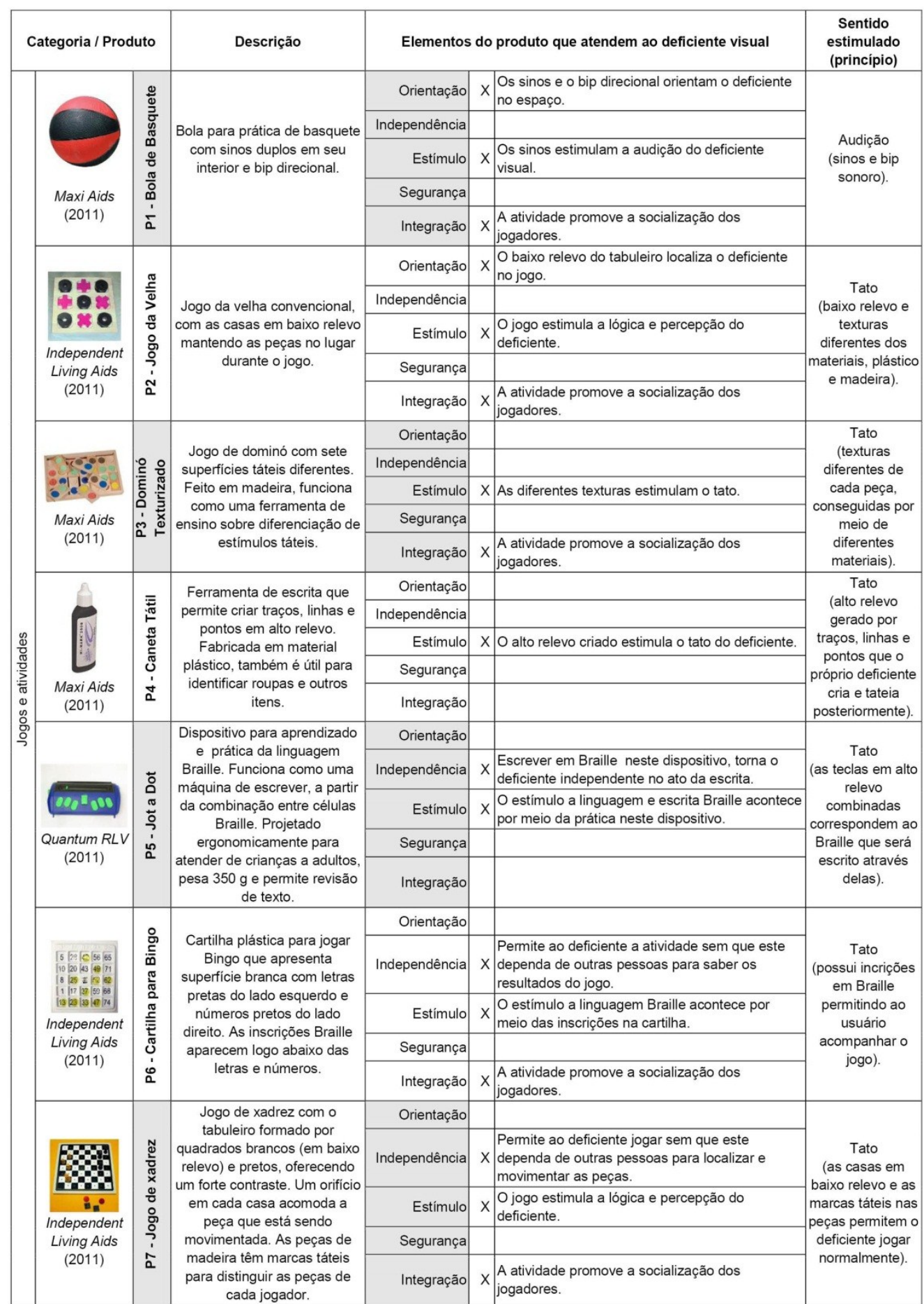

Revista Produção Online, Florianópolis, SC, v.13, n. 1, p. 257-289, jan./mar. 2013. 


\section{APÊNDICE B - GUIA DE REFERÊNCIA PARA O DESENVOLVIMENTO DE PRODUTOS PARA O DEFICIENTE VISUAL}

Figura 12 - Excerto da página 1 do Guia de Referência
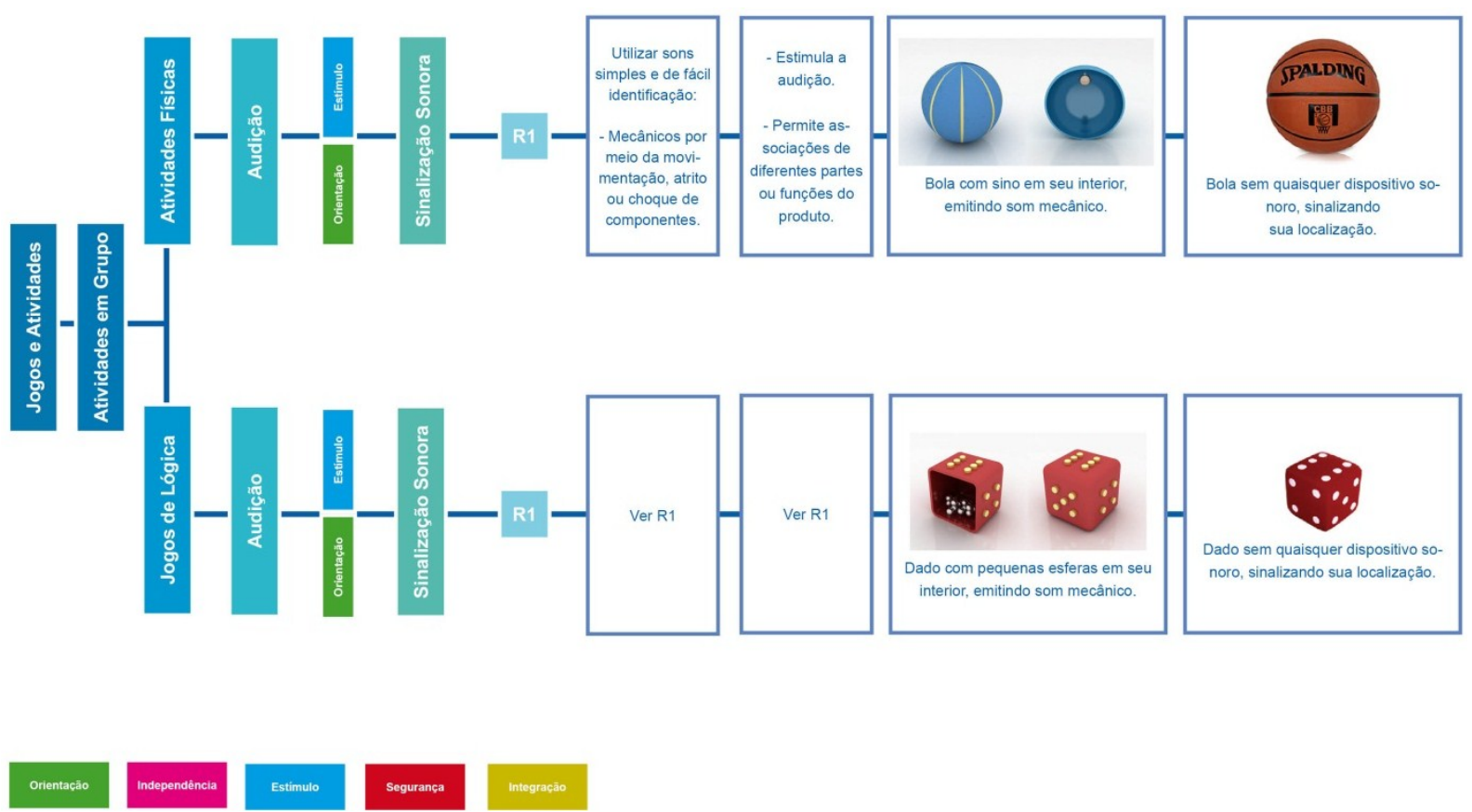

Figura 13 - Excerto da página 2 do Guia de Referência

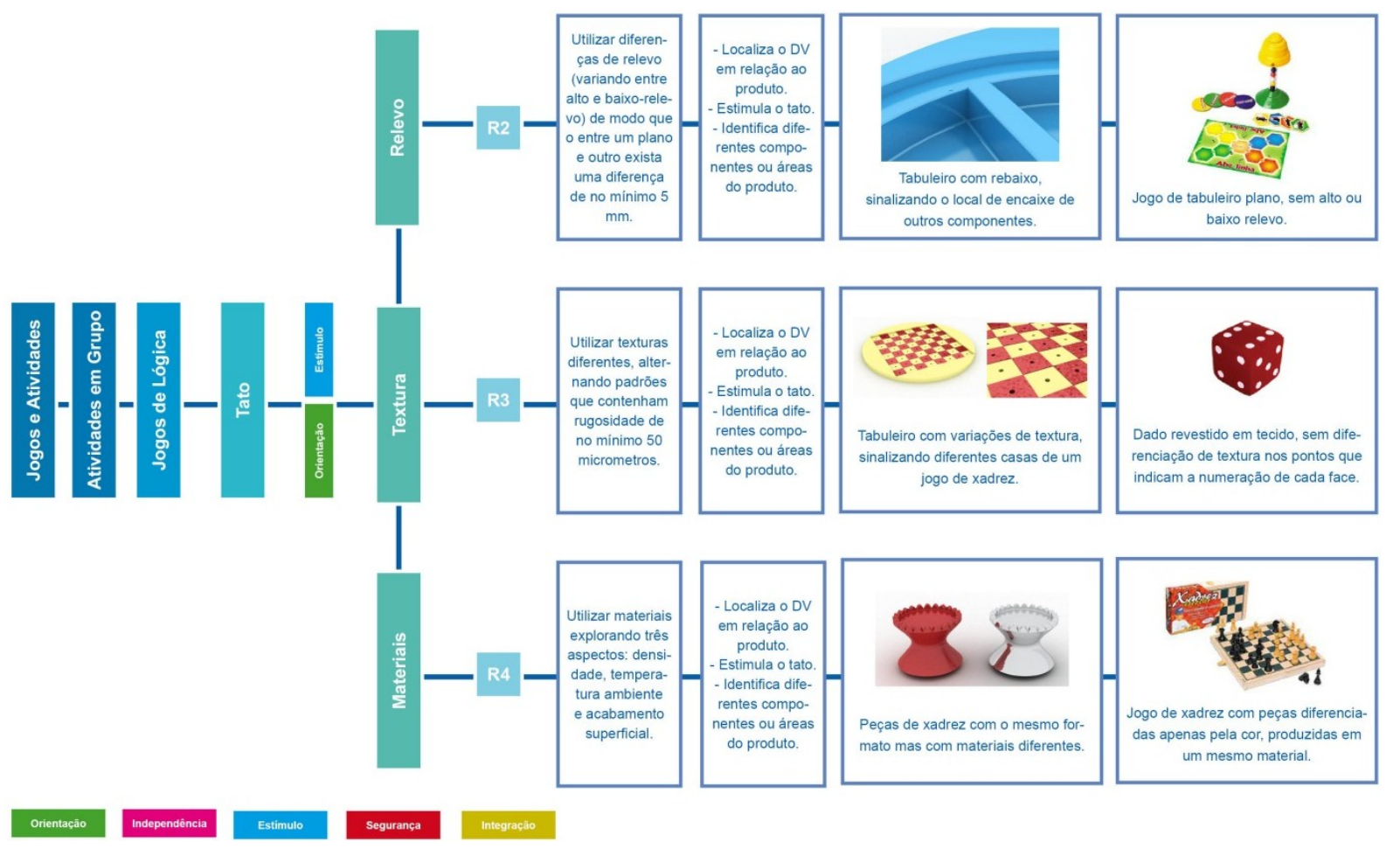

Revista Produção Online, Florianópolis, SC, v.13, n. 1, p. 257-289, jan./mar. 2013. 